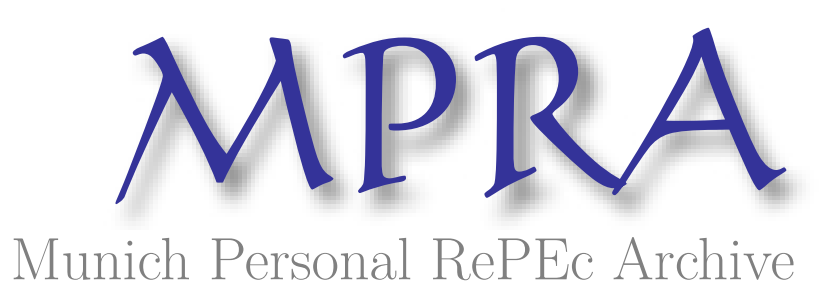

\title{
Towards Regional Monetary Unions through Blockchain Networks
}

Hegadekatti, Kartik

1 April 2017

Online at https://mpra.ub.uni-muenchen.de/82838/

MPRA Paper No. 82838, posted 25 Nov 2017 18:19 UTC 


\section{Towards Regional Monetary Unions Through Blockchain Networks}

\section{Dr.Kartik H}

\section{Author's email-dr.kartik.h@gmail.com}

\section{$\underline{\text { ABSTRACT }}$}

The concept of political and economic integration has not progressed beyond the concept of a Nation-state. The primary reason is the trust deficit among citizens in a supra-national entity. We can use Blockchain systems-which are trustless networks-to resolve this issue. We can float a Regional Cryptocurrency (RCC) which can bring about a successful Regional Monetary Unions (RMU) amongst a group of nations in a transparent manner.

This paper deals with the idea of realising a monetary union through Blockchain networks. Firstly I describe the basics of cryptocurrencies and RSBCs. Then we shall evaluate how RMUs have failed due trust deficit among citizens of members of RMU. We then analyse as to how Blockchain networks can be a solution to these problems. The paper concludes by summarizing the difficulties and solutions regarding successful formation of Regional Monetary Unions.

\section{INTRODUCTION}

A cryptocurrency is a medium of exchange using cryptographic techniques to safeguard transactions and also manage the formation of additional units of the currency.

A BlockChain is a widely disseminated archive of data that maintains a continually-expanding register of records fully and reliably protected from any alteration or modification. Each block has a timestamp and link to the preceding block. 
A Crypto wallet is an encrypted electronic device that allows an individual to make electronic cryptocurrency transactions. Each wallet will have a public key visible to anyone. But it can be operated by only a person who has a private key. Transactions on the cryptocoin network are usually anonymous.

When people send cryptocoins to each other, someone has to keep account of who spent how much at what time. In case of fiat money (or paper money) it is done by banks (known as Trusted Third Parties, for which they charge a commission).But in case of Cryptocoins, it is registered on a ledger called BlockChain (with nil or minimal fees).

The cryptocoin network makes this possible by detailing all the transactions made during a certain timeframe into a list. This list is known as a block. A certain set of people called 'miners' verify these transactions mathematically and register them on the BlockChain. Those bona-fide miners who have successfully verified the transactions are paid freshly created Cryptocoins. This is how miners are rewarded, and new cryptocoins are generated. This is also the reason why no transaction costs are levied, as the network (in the form of miners) verifies the transactions.

Bitcoin is a peer-to-peer based cryptocoin which is not backed by any commodity and (unlike fiat money) carries no sovereign guarantee whatsoever.

Regulated and Sovereign Backed Cryptocurrencies (RSBC), on the other hand are government backed cryptocurrency akin to paper currency, but in digital form. In this system, the cryptocoins (known as NationCoins) are backed by Sovereign Guarantee.

They are run on a highly secure Controlled BlockChain $(C B C)^{[1]}$ in which Sovereign backed Cryptocurrencies will be transacted without any 
hassles. NationCoins are completely managed by the Sovereign Authority i.e. the Government.

This system is based on the K-Y Protocol ${ }^{[2]}$. The K-Y Protocol is a set of rules and instructions to implement the Regulated and Sovereign Backed Cryptocurrency (RSBC) system.

\section{The advantages of a Monetary Union:}

There are several significant benefits of having a Monetary Union. These are principally the benefits of fixed exchange rates, and are as follows:

\section{1) Boost to trade}

Trade between members of a Monetary Union will increase because of the benefits of sharing a currency. There are no exchange rates due to which seamless trade and foreign exchange becomes possible.

\section{2) Lower transaction costs}

Transaction costs are decreased as no commissions need be paid to financial middlemen.

\section{3) Certainty of investment}

The Monetary Union creates certainty as companies can predict the cost of raw materials in the market of all member nations of the Union. They can also set a common price for their products, i.e. they can plan and invest with certainty.

\section{4) Discipline during difficulty}

Members of the Union cannot take the easy route out of an economic difficulty like inflation (through devaluation).

5) Employment generation: Increased trade will create jobs in industries that experience increased production. 


\section{6) Transparency}

Businessmen and travellers can more easily compare prices of resources, goods, and services.

\section{The Disadvantages of a Monetary Union}

There are several demerits of a Monetary Union. These principally result from the trust deficit and rigidity of such a Union, and are as follows:

\section{1) Asymmetric shocks}

Asymmetric shocks are external economic shocks that have different impacts on different economies. A political/economic/geographic event in one part of the world may affect the economy of only some members of the Union. In that case, having a single policy might not suit all members.

\section{2) A single policy for many economies}

Having a single interest rate is not practical when a diverse range of economies and economic circumstances exist in a RMU. Even within a single nation, great diversity can exist, signifying that a common economic policy might be not work.

\section{3) Loss of economic autonomy}

Once a country becomes a member of a Monetary Union, National Central Banks, lose their ability to use interest rates to achieve independent macro-economic objectives. After the financial crisis and global recession, recession-affected nations like Greece were unable to reduce interest rates unilaterally as they were part of a Monetary Union i.e Euro.

Monetary unions have been attempted from quite some time since the dawn of nation-states. 
The political history of human societies has followed a course of ever increasing agglomeration into larger and larger units. Individuals become family. Families coalesced to form clans. Clans were part of a tribe. A family of tribes become a kingdom. With the advent of the concept of people - centric rule, Nation states arose. And since then, the agglomeration process has not moved forward. The next logical step would be the formation of regional supranational entitiies, that can later be forged into a single global world order. Communism tried to forge a supra-national setup under the aegis of the USSR. But that failed. Eventually the Soviet Union collapsed with the member nations reverting back to their national identities.

The EU (European Union) was another experiment where member nations were to first get integrated economically through a monetary union, slowly moving on to a political and cultural union. The monetary union held for a time. But recently with Brexit, the European Union may no longer withstand a seamless monetary union. Though the monetary union still holds, it is perhaps other economic and political issues of the EU that triggered Brexit. With other things staying the same and maintaining a Pre-EU status quo, a successful monetary union might have played out differently. The EU did wither over the PIGs crisis, though temporarily.

The primary reason for the failure of monetary unions appears to be (a lack of) trust among the member entities. Absence of trust beyond national leanings tends to weaken a monetary union in spite of codification of the monetary union in the form of agreements and treaties. A supra-national entity demands that citizens of member nations trust it at least as much (if not more) as they trust their government. But when certain policies appear to benefit some member nations more than others there is a trust imbalance, triggering regional resentment and discontent. 
This lack of trust can be best resolved by using Blockchain technology to bring about a Regional Monetary Union. A Blockchain network is by nature, a trustless network. As such, people using it need not depend on any third party to execute their work. The network does it for them at zero cost.

The idea is to float a Regional CryptoCurrency (RCC) between two or more member nations who desire to bring about a Regional Monetary Union among them.

The advantages of such a RCC are numerous-

\section{1) It Will Be Fast}

When you pay check to any bank, your Money is held by the bank from a few hours to few days. In the same way, international fund transfers take a long time. This is because; the banks have to verify that the Money is really available for the transaction to occur. With RCC this can happen a lot faster as the network automatically verifies the transactions for the customers.

\section{2) Minimal Transaction Cost}

Whenever you transact with your credit card or any kind of Banking service, a small amount is deducted from your account as service charges. With RCC, such costs will be minimal and most of the times it will free.

\section{3) Circumventing the Triffin Dilemma}

The USA needs to print Dollars and pay countries to buy products they produce. But by printing more Dollars, the US government is inadvertently causing inflation of its own national currency. Now the US government faces a dilemma. 
If it prints more currency, it may end up harming its own economy. If it does not supply the world with Dollars, the world economy will face a Dollar crunch leading to a host of problems associated with deflation. This creates a situation where the USA is in a state of eternal trade and current account deficit. This conflict between the domestic economic interest and international economic obligations is called Triffin dilemma, named after Robert Triffin who identified it.

By introducing RCCs, this problem of Triffin dilemma can be circumvented (at least in the RMU). Nations of the RMU will be on an equal footing in the economic sense as no member will be a burden on the country facing the Triffin Dilemma.

\section{4) The RCC Can Be Designed To Be Non-Inflationary}

Cryptocurrencies usually have a fixed maximum number of units limited by computing power. That means that beyond that particular number, the Cryptocurrency cannot grow. [The maximum possible number for Bitcoin is 21 million].If a similar cap is put on the supply of RCC there will be minimal or no inflation.

Inflation is basically "more money chasing fewer Goods." But if RCC supply will be fixed, there will be no inflation. If the stakeholders, i.e. the people of the members of RMU still want to continue the inflationary model of growth, $1 \%$ inflation can be built into the RCC system.

\section{5) Sovereign Backing}

Central Banks, multiple governments, and a Monetary Union Authority will regulate RCC. There will thus be sovereign (government) backing to RCC. By introducing governments into the Cryptocurrency equation, one can discourage criminal elements from misusing Cryptocurrencies to commit Crimes and Frauds. 


\section{6) A Single Integrated Transaction System}

The whole geographical area of the Monetary Union can have a Single Integrated Transaction System (SITS). This will lead to uniformity in Commercial and Accounting standards. It will have immense impact on consumer satisfaction. As a result, consumers will find shopping and business transactions to be seamless and hassle free. A single RCC Card can be used to shop all across the Monetary Union.

This will also allow for better fiscal intercourse between Nations of the Monetary Union as any deficit can be offset by RCC loans, which can then be traded for Dollars, Euros, other hard currencies or the local currency itself.

7) Ease of Business-The whole world can trade with Regional Monetary Union in only one currency i.e. RCC.

\section{8) Governments Can Transact Using RCC.}

This will eliminate the need to transact using other currencies. There are several benefits in such kind of transactions.

a. Trading countries need not have currency reserves. Since RCC will be pegged to their local currency (i.e. fiat paper money), all they need to have is enough liquidity in their own currency.

b. There will be minimal or no Balance of Trade (BOP) crisis between members of a Monetary Union as the use of other currencies (as reserve currency) will be bypassed.

c. Swap agreements become easier and less costly. Say for instance, Country A (Member of a Monetary Union X) wants to trade with Country $B$ (Member of a Monetary Union $Y$ ) but does not have enough Dollars. All that Country A has to do is sell its existing RCC reserves to (say) Country C (Member of a Monetary Union X) and obtain Dollars (at 
a fixed Exchange rate). Thus, there is hardly any need to keep a running Dollar Account.

\section{9) Increased Savings and Investments}

Every day, billions of Dollars are paid across the world as transaction costs. By using RCCs, at least a fraction of that cost is eliminated for the members of the Monetary Union. That translates into several millions of Dollars left in the hands of consumers. This will lead to increased savings, increased investment and hence growth of the respective economies.

This conflict between the domestic economic interest and international economic obligations is called the Triffin dilemma, named after Robert Triffin who identified it.

By introducing RCCs, this problem of Triffin dilemma can be circumvented (at least partially). Nations of the world will be on an equal footing in the economic sense as no country needs to face the Triffin Dilemma.

\section{The Idea of a Soft Monetary Union}

A monetary union involves two or more nations sharing the same currency without them having any further integration. Here, I differentiate between a Hard Monetary Union and a Soft Monetary union. In a Hard Monetary Union, the members of the union have a single, common fiat paper (and Crypto) currency. Whereas in a Soft Monetary Union, the members of the union will have a single, common cryptocurrency. But they will not have a common paper currency. The members will have their own unique fiat national paper currencies plus a single common regional cryptocurrency with a dynamic exchange rate vis-a-vis their national currencies. 
The RCC need not replace the existing national paper currencies in the member nations (a Soft Monetary Union). But it will be supplementing those nations' fiat currencies. Reserves no longer need be held in hard currencies. Currency swaps will be easier and streamlined. Other nations can easily trade with the RMU like a single trade bloc. Economic intercourse and commerce between the member nations will be simplified.

We can define various phases for a successful RMU based on a RCC.

Phase I: - Member nations use RCC for internal accounting, BOT and BOP settlements.

Phase II: - Businessmen and tourists from RMU nations can use it in other member nations of same RMU.

Phase III: - The common public can use it for investment and day - to day transactions.

Phase IV: - Free inter - convertibility between the National currencies of member states and RCC.

Phase V: - RCC becomes the dominant mode of transaction within member nations.

The RCC can be designed in such a way that there is free inter-

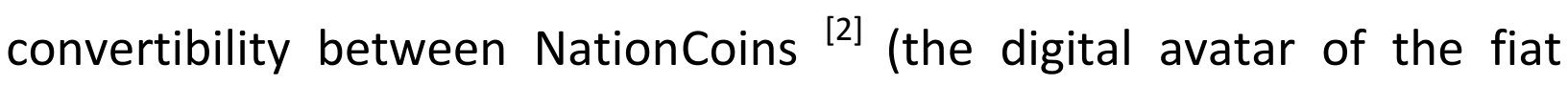
paper currency) and RCC.

The RCC can, later on, give way to a continent-wide currency [like CoinAsia ${ }^{[3]}$ finally leading to the establishment of WorldMoney-The global cryptocurrency ${ }^{[4]}$. 


\section{CONCLUSION}

The concept of political and economic integration has not gone beyond the concept of a Nation-state. The primary reason is the trust deficit among citizens in a supra-national entity. We can use Blockchain technology-which are trustless networks-to resolve this issue. We can float a RCC which will bring about a successful RMU in a transparent manner.

We have seen how RMU provides for many advantages. We also identified the various phases in which RMU can be implemented.

RMUs will, in future, through RCCs, give rise to a continent wide and later a world-wide single economic order under a common currency.

\section{REFERENCES}

[1] Hegadekatti, Kartik and S G, Yatish, Roadmap for a Controlled Block Chain Architecture (August 13, 2016). Available at SSRN: https://ssrn.com/abstract $=2822667$

[2] Hegadekatti, Kartik and S G, Yatish, The K-Y Protocol: The First Protocol for the Regulation of Crypto Currencies (E.G.-Bitcoin)(February 13, 2016). Available at SSRN: https://ssrn.com/abstract $=2735267$ or http://dx.doi.org/10.2139/ssrn.2735267

[3] Hegadekatti, Kartik, CoinAsia: A Sovereign Backed Cryptocurrency and Blockchain for Asia (December 22, 2016). Available at SSRN: https://ssrn.com/abstract=2888721

[4] Hegadekatti, Kartik, WorldMoney - The International Sovereign Backed Cryptocurrency (December 22, 2016). Available at SSRN: https://ssrn.com/abstract=2888773 